\title{
Analisa Kepuasan Mahasiswa Terhadap Kegiatan Belajar Mengajar Di Program Studi Teknik Informatika Universitas Mataram Menggunakan Metode Importance Performance Analysis
}

\author{
(Analysis Of Student Satisfaction To Learning Activities At Informatic Engineering Department Of \\ Mataram University Using Importance Performance Analysis Method)
}

\author{
Nadiyasari Agitha ${ }^{[1]^{*}}$, Diaz Guntur Febrian ${ }^{[2]}$ \\ ${ }^{1}$ Jurusan Teknik Informatika, Fakultas Teknik, Universitas Mataram \\ Jl. Majapahit 62, Mataram, Lombok NTB, INDONESIA \\ ${ }^{2}$ Dinas Komunikasi, Informatika dan Statistik Provinsi NTB \\ Jalan Udayana No. 14 Mataram, Lombok NTB, INDONESIA \\ Email: nadiya@unram.ac.id, diazgunturfebrian26@gmail.com
}

\section{*Penulis korespondensi}

\begin{abstract}
The questionnaire was used as an instrument to analyze student satisfaction with teaching and learning activities. The Informatics Engineering Study Program (PSTI) Mataram University has used a questionnaire to analyze student satisfaction. Besides, it is not integrated into the Academic Information System so that it cannot find out who has filled out the questionnaire. The questionnaire cannot be used as an assessment of lecturer performance after teaching in the semester. Importance Performance Analysis (IPA) is a method used to measure the level of conformity of how much the customer is satisfied with the performance of the Study Program. The IPA method produces a percentage value that is owned by each lecturer to improve future teaching and makes it easier for the Chairperson of PSTI to see the performance of each lecturer in his teaching.
\end{abstract}

Keywords: Kuesioner, Metode IPA, kuadran, MOS

\section{PENDAHULUAN}

Kuesioner adalah instrumen penelitian yang digunakan untuk pengumpulan data. Dalam kuesioner, responden disediakan sekumpulan pertanyaan yang sedianya akan dijawab. Responden adalah orang yang diberikan kuesioner untuk dimintai pendapatnya [1] Salah satu manfaat dari kuesioner adalah untuk perbaikan dan peningkatan kualitas dari suatu jasa atau produk. Dengan meminta keterangan (kritik dan saran) dari pengguna jasa atau produk tersebut, dapat diketahui apa yang perlu diperbaiki maupun ditambahkan terhadap jasa atau produk tersebut.

Kegunaan kuesioner lainnya adalah sebagai instrumen untuk menganalisa kepuasan mahasiswa suatu terhadap kegiatan belajar mengajar. Mahasiswa yang merupakan pelaku dalam proses belajar mengajar adalah salah satu responden yang vital untuk dimintai pendapat dan saran terhadap kualitas belajar mengajar guna meningkatkan dan memperbaiki kualitas kegiatan belajar mengajar. Untuk mempercepat proses penggunaan kuesioner dan pengolahan data kuesioner, digunakanlah Teknologi Informasi.

Program Studi Teknik Informatika (PSTI) Universitas Mataram telah menggunakan kuesioner digital dengan laman akses http://angket.if.unram.ac.id/angket/public. Mahasiswa dapat mengisi kuesioner yang terkait dengan kegiatan belajar mengajar, sedangkan dosen dapat menjadi evaluator dalam mengolah hasil kuesioner. Pengisian kuesioner dijadwalkan di akhir semester sebagai syarat untuk dapat mengisi Kartu Rencana Studi (KRS) semester berikutnya.

Permasalahan yang timbul dengan menggunakan kuesioner digital yang dimiliki PSTI adalah kuesioner ini tidak terintegrasi dengan Sistem Informasi Akademik (SIA) yang dimiliki oleh Universitas Mataram, sehingga data siapa saja yang telah mengisi tidak akan terhubung dengan KRS masing-masing mahasiswa. Proses tersebut mengakibatkan terkendalanya pengisian KRS dikarenakan harus melihat manual siapa saja yang sudah mengisi kuesioner. Data pertanyaan dan evaluasi yang dilakukan dalam kuesioner digital juga belum memiliki prioritas yang digunakan untuk mengukur hasil kuesioner. Sehingga hasil kuesioner hanya digunakan sebagai validitas mahasiswa untuk mendapatkan KRS. Selain itu, kuesioner tidak dapat digunakan sebagai penilaian performa dosen setelah mengajar pada semester tersebut.

Importance Performance Analysis (IPA) adalah metode yang digunakan untuk mengukur tingkat kepuasan konsumen. Dalam hal ini pelanggan merupakan mahasiswa yang akan menilai kinerja dari Dosen pada PSTI [2]. Metode ini menganalisis hasil dan membaginya menjadi 4 kuadran yaitu Q1, Q2, Q3 dan Q4 dengan sumbu x berfokus pada performance dan sumbu $\mathrm{Y}$ berfokus pada importance. Pada metode ini akan menyimpulkan kualitas yang dimiliki dosen dari hasil kuesioner berdasarkan 4 kuadran tersebut.[3]

Berdasarkan permasalahan diatas, pengimplementasian metode IPA merupakan metode yang tepat digunakan karena metode ini berfokus pada identifikasi elemen 
kritikal yang dapat dievaluasi [4]. Elemen tersebut nantinya akan menentukan kesimpulan kuadran mana yang dimiliki oleh dosen sehingga dapat meningkatkan performa untuk kedepannya. Kesimpulan tersebut juga akan mempengaruhi penilaian kinerja dosen untuk terus dapat ditingkatkan.

\section{TINJAUAN PUSTAKA}

Penelitian yang mengukur tingkat kepuasan mahasiswa dengan menggunakan metode IPA pada Politeknik Negeri Malang [5] menjelaskan bahwa dalam satu pertanyaan kuesioner terdapat dua jenis penilaian, yaitu penilaian yang berdasarkan fakta dan penilaian harapan yang diinginkan oleh user. Nilai skor dari setiap pertanyaan yang diberikan yang menjabarkan parameter dan komponen yang akan diukur. Jawaban kuesioner mahasiswa akan dianalisis menghasilkan nilai berupa persentase. Diagram kartesius digunakan untuk menampilkan prioritas yang akan diperbaiki. Pada penelitian yang dilakukan menggunakan kesimpulan berupa angka dan persentase yang akan menentukan performa yang dimiliki setiap dosen.

Penelitian lainnya yaitu penelitian yang menganalisis Metode IPA menganalisa kepuasan mahasiswa terhadap pelayanan Universitas dengan membandingkan antara harapan dan kinerja. Analisis menghasilkan letak factor yang mempengaruhi kepuasan mahasiswa dengan menggunakan Diagram kartesius sebagai visualisasinya. Sedangkan metode Kano dapat menakar tingkat prioritas terhadap komponen layanan yang telah dikelompokkan sebelumnya oleh metode Kano [6]. Pada penelitian yang dilakukan, hanya menggunakan metode IPA untuk melakukan analisis terhadap diagram kartesius dan kesimpulannya menggunakan diagram batang.

Dalam membangun sistem informasi analisa kuesioner penggunaan layanan internet menggunakan metode Importance Performance Analysis (IPA) dan Customer Satisfaction Index (CSI) (studi kasus Universitas Mataram). Mahasiswa diberikan kuesioner untuk menilai Sistem informasi sehingga mendapatkan tingkat kepuasan terhadap Sistem Informasi tersebut serta layanan internet di Universitas Mataram. Dari hasil analisis menggunakan metode IPA, terdapat beberapa komponen yang menghasilkan nilai yang rendah. Nilai rendah tersebut akan menjadi komponen untuk terus ditingkatkan [7]. Pada penelitian yang dilakukan peneliti, metode IPA yang digunakan diperuntukkan menilai analisis tingkat kepuasan mahasiswa terhadap kinerja dosen selama melakukan pengajaran pada semester tersebut.

Penelitian yang berkaitan dengan mengevaluasi guru dalam pelaksanaan development program. Guru yang dievaluasi adalah guru matematika dari beberapa daerah dengan mengadopsi skala likert sebagai acuannya. Hasil penelitian menunjukkan bahwa struktur program, administrator kesiapan, dan dukungan institusional berada dalam kategori High Importance, sedangkan kebutuhan guru serta nilai-nilai \& motivasi termasuk dalam kategori Low Importance. Selain itu, kinerja aktual untuk struktur program dan nilai-nilai \& motivasi terungkap dalam kategori Kinerja Tinggi, sementara kesiapan administrator, kebutuhan guru, serta dukungan kelembagaan berada dalam kategori Kinerja Rendah. Atribut prioritas utama yang perlu diperbaiki sesuai dengan peta kuadran IPA adalah tentang simulasi model pembelajaran, kesediaan studi tentang perangkat pembelajaran, tersedianya anggaran program dan kegiatan, ketersediaan media sebagai alat bantu kegiatan dan menyiapkan penghargaan atas kinerja guru [8].

Penelitian yang dilakukan untuk meninjau e-learning pada pendidikan tinggi menggunakan metode IPA, menghasilkan teknologi apa di dalam e-learning yang perlu ditingkatkan dan teknologi yang dapat membantu pelaksanaan HEI's Malaysia dalam meningkatkan performa e-learningnya [9]. Pada penelitian yang dilakukan pihak PSTI dapat fokus pada atribut yang diprioritaskan dan penggunaan sumber daya dapat digunakan dengan lebih efisien. Data hasil kuesioner akan dianalisa menggunakan metode IPA dan memberikan keluaran informasi berupa Diagram kartesian yang menunjukan atribut - atribut pada suatu Koordinat berdasarkan dari fakta dan harapan mahasiswa. Koordinat suatu atribut dapat menentukan tingkat prioritasnya.

\section{METODE PENELITIAN}

Penelitian yang dilakukan dengan metode IPA (Importance Performance Analysis) untuk analisa kepuasan Mahasiswa terhadap proses belajar mengajar adalah dengan membuat sistem informasi kueisoner. Secara umum proses penelitian dapat dijabarkan pada Gambar 1.

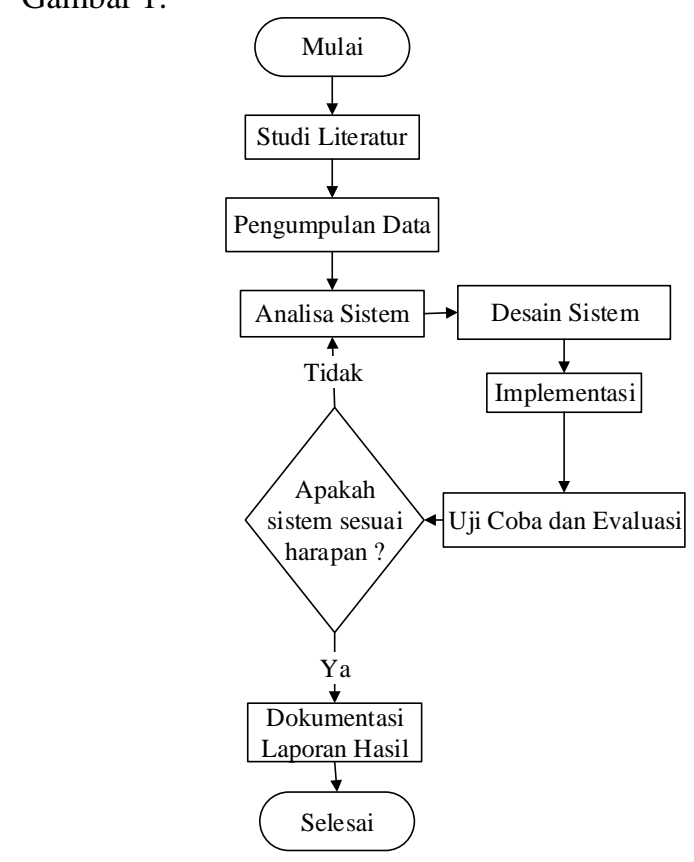

Gambar 1. Diagram alur penelitian 


\section{A. Studi Literatur}

Memahami literatur merupakan tujuan utama dari melakukan studi literature. Literatur yang dimaksud dalah buku, jurnal dan hal-hal yang terkait dengan penelitian., diantaranya adalah bedah internet. Studi literatur berupa kajian pustaka beserta dasar teori yang terkait, meliputi : sistem informasi berbasis website, kuesioner online, analisa berbasis IPA, serta pertanyaan-pertanyaan tentang kepuasan Mahasiswa terhadap proses belajar mengajar.

Dari hasil studi literatur di Program Studi Teknik Informatika Universitas Mataram dapat diketahui kondisi yang terjadi di program studi. Program studi membutuhkan sistem kuesioner online yang tidak hanya dapat mengukur tingkat kepuasan Mahasiswa terhadap kegiatan belajar mengajar, tetapi juga sebagai penunjang performa dosen kedepannya.

\section{B. Pengumpulan Data}

Data yang digunakan dalam penyusunan penelitian diantaranya adalah data primer dan data sekunder. Data primer diperoleh berdasarkan kuesioner yang diisi oleh mahasiswa. Data tersebut akan dianalisis menggunakan metode IPA. Sedangkan data sekunder adalah pertanyaanpertanyaan yang dikumpulkan dengan menggunakan metode observasi dan wawancara kepada pihak lain yang menentukan pertanyaan kepuasan terhadap mahasiswa. Pihak tersebut adalah pihak penjaminan mutu Universitas Mataram.

Untuk mengukur ekspektasi/harapan layanan menggunakan empat skala penilaian yaitu :

a. Skor 1 (Tidak Penting), jika tingkat harapan dari atribut layanan tidak penting.

b. Skor 2 (Cukup Penting), jika tingkat harapan dari atribut layanan cukup penting.

c. Skor 3 (Penting), jika tingkat harapan dari atribut layanan penting.

d. Skor 4 (Sangat Penting), jika tingkat harapan dari atribut layanan sangat penting.

Sedangkan untuk mengukur tingkat persepsi layanan menggunakan empat skala penilaian yaitu :

a. Skor 1 (Tidak Baik), jika merasa tidak puas dengan layanan yang diterima.

b. Skor 2 (Cukup Baik), jika merasa cukup puas dengan layanan yang diterima.

c. Skor 3 (Baik), jika merasa puas dengan layanan yang diterima.

d. Skor 4 (Sangat Baik), jika merasa sangat puas dengan layanan yang diterima.

\section{Analisa Sistem}

Sistem informasi kepuasan mahasiswa terhadap kegiatan belajar mengajar yang akan dibuat dapat dijelaskan secara garis besar pada Gambar 2, Gambar 3, Gambar 4 dan Gambar 5.

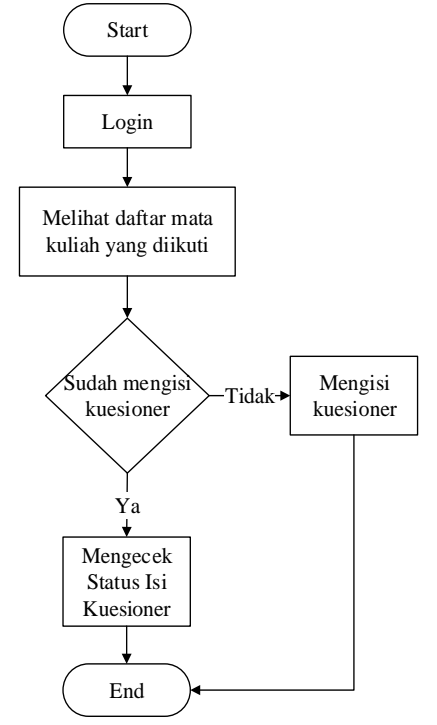

Gambar 2. Flowchart penggunaan sistem oleh mahasiswa

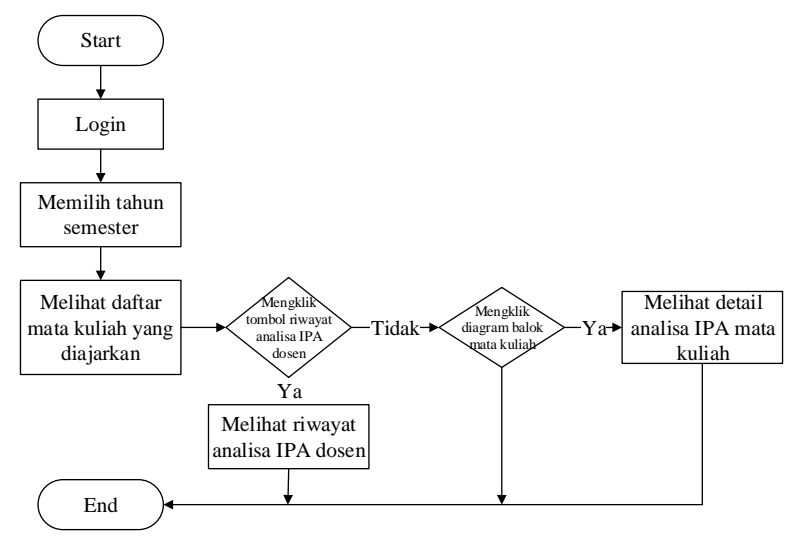

Gambar 3. Flowchart penggunaan sistem oleh dosen

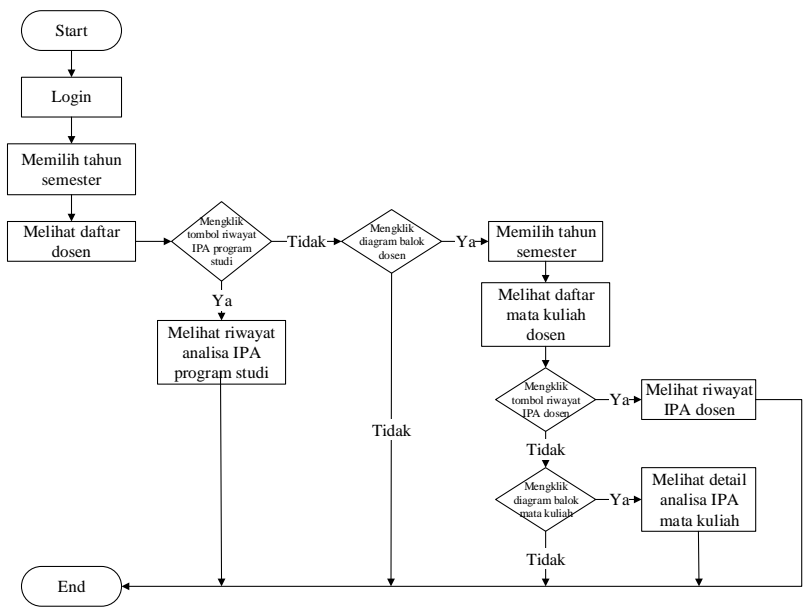

Gambar 4. Flowchart penggunaan sistem oleh Ketua Program Studi

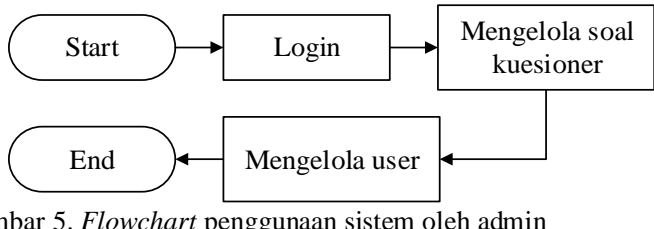

Gambar 5. Flowchart penggunaan sistem oleh admin 


\section{Desain Sistem}

Tahap desain merupakan tahap perancangan sistem atau penggambaran tentang sistem yang akan dibuat. Pada tahap desain ini terdiri dari use case diagram, entity relational diagram, tabel database, class diagram, sequence diagram, activity diagram, antarmuka (interface) dan Importance Performance Analysis (IPA). D.1 Use Case Diagram

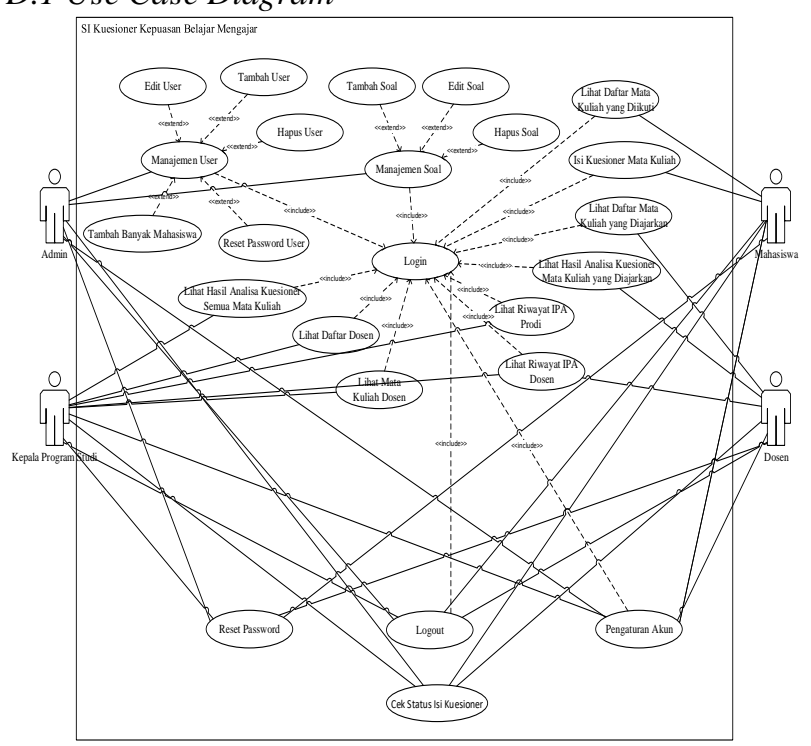

Gambar 7. Use Case Diagram

\section{D.2 Entity Relation Diagram}

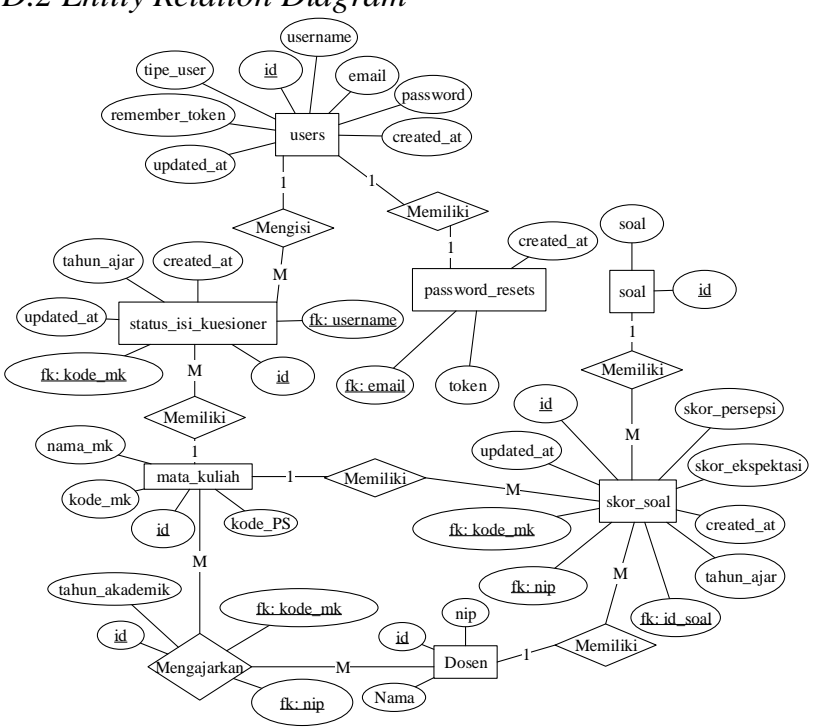

Gambar 8. Entity Relation Diagram

Pada gambar diatas dijelaskan bahwa terdapat entitas user yang saling terhubung dengan status isi kuesioner dan password reset. Status isi kuesioner yang akan diisi sesuai dengan mata kuliah yang diambil mahasiswa. Mata kuliah tersebut diampu oleh dosen. Dosen mempunyai skor soal yang didapat dari kumpulan beberapa pertanyaan yang tersimpan dalam entitas soal.

\section{D.3 Class Diagram}

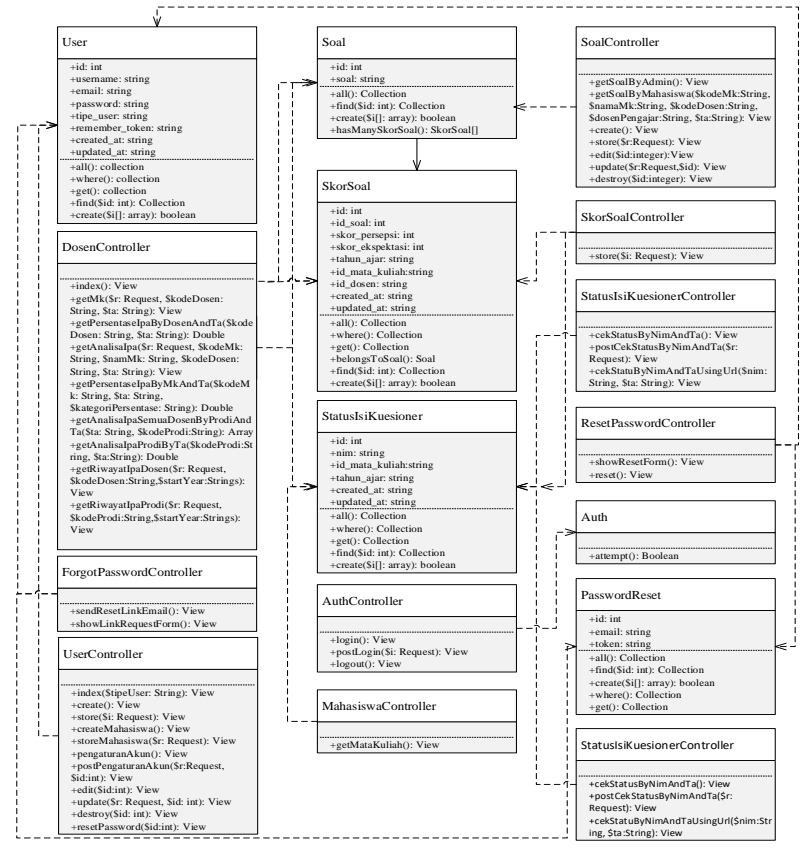

Gambar 9. Class Diagram

Class diagram yang dikelompokkan berdasarkan MVC atau Model, View dan Controller. Pembuatan MVC didasarkan pada penggunaan software maupun desain yang berorientasi objek.

\section{HASIL DAN PEMBAHASAN}

Hasil dan pembahasasn menjelaskan implementasi dari perancangan sistem yang telah dijelaskan pada bab sebelumnya, yang terdiri dari implementasi database, implementasi class dan implementasi interface serta pengujian sistem.

\section{A. Implementasi Database}

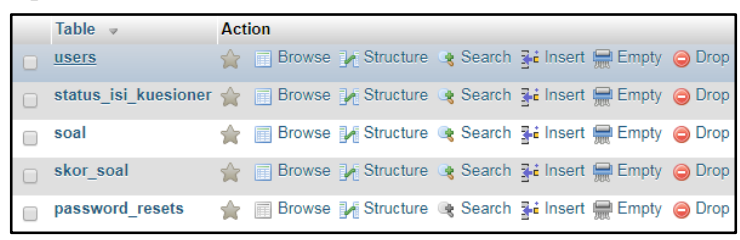

Gambar 10. Database sistem informasi kepuasan belajar mengajar

Implementasi database dibuat menggunakan MySQL sebagai software yang membantu pembuatan database. Pembuatan entitas maupun atribut telah disesuaikan dengan perancangan yang terdapat pada ERD.

\section{B. Implementasi Class}

\begin{tabular}{|c|c|c|c|}
\hline (1) PasswordReset & 8/4/2017 1:35 PM & PHP File & $1 \mathrm{~KB}$ \\
\hline [0] SkorSoal & 8/4/2017 2:53 PM & PHP File & $1 \mathrm{~KB}$ \\
\hline [्] Soal & 8/4/2017 2:53 PM & PHP File & $1 \mathrm{~KB}$ \\
\hline [ StatuslsiKuesioner & 8/4/20171:35 PM & PHP File & $1 \mathrm{~KB}$ \\
\hline [e] User & 8/4/2017 2:53 PM & PHP File & $1 \mathrm{~KB}$ \\
\hline
\end{tabular}

Gambar 11. Implementasi class model 


\begin{tabular}{|c|c|c|c|}
\hline AuthController & 8/4/2017 1:35 PM & PHP File & $2 \mathrm{~KB}$ \\
\hline [9] DosenController & 8/4/2017 3:44 PM & PHP File & $5 \mathrm{~KB}$ \\
\hline [] ForgotPasswordController & 8/4/2017 1:35 PM & PHP File & $2 \mathrm{~KB}$ \\
\hline [] HomeController & 8/4/2017 1:35 PM & PHP File & $1 \mathrm{~KB}$ \\
\hline []ㅁ] MahasiswaController & 8/4/2017 2:55 PM & PHP File & $2 \mathrm{~KB}$ \\
\hline [0 ResetPasswordController & 8/4/2017 1:35 PM & PHP File & $1 \mathrm{~KB}$ \\
\hline 픔 SkorSoalController & 8/4/2017 2:53 PM & PHP File & $2 \mathrm{~KB}$ \\
\hline [5] SoalController & 8/4/2017 3:19 PM & PHP File & $2 \mathrm{~KB}$ \\
\hline [] StatusisiKuesionerController & 8/4/2017 1:35 PM & PHP File & $1 \mathrm{~KB}$ \\
\hline [0] UserController & 8/4/2017 2:53 PM & PHP File & $3 \mathrm{~KB}$ \\
\hline
\end{tabular}

Gambar 12. Implementasi class controller

Pada implementasi class telah dibagi berdasarkan model, view, controller (MVC). Implementasi class disesuaikan dengan class diagram yang telah dirancang sebelumnya.

\section{Tampilan Aplikasi}

Beberapa tampilan dari aplikasi dapat dilihat pada gambar berikut.

\begin{tabular}{|c|c|c|c|}
\hline \multicolumn{4}{|c|}{ Daftar Mata Kuliah Tahun Akademik 2015 Genap } \\
\hline Tahu & Akademik 2015 Genap V & & \\
\hline No. & Mata Kuliah & Dosen Pengajar & Kuesioner \\
\hline 1 & Sistem Informasi Manajemen & Ir. Sri Endang Anjarwani, M.Kom & $\mathbb{E}$ \\
\hline 2 & Pemrograman Berorientasi objek & Royana Afwani, ST., MT. & $\checkmark$ \\
\hline 3 & Teori Bahasa dan Automata & Moh. Ali Albar, ST., M.Eng. & (8) \\
\hline
\end{tabular}

Gambar 13. Halaman daftar mata kuliah oleh mahasiswa

Halaman daftar mata kuliah dapat digunakan oleh mahasiswa untuk melihat mata kuliah apa saja yang diambil pada semester berjalan. Pada laman ini diberikan keterangan mana sajakah kuesioner yang telah diisi atau yang belum.

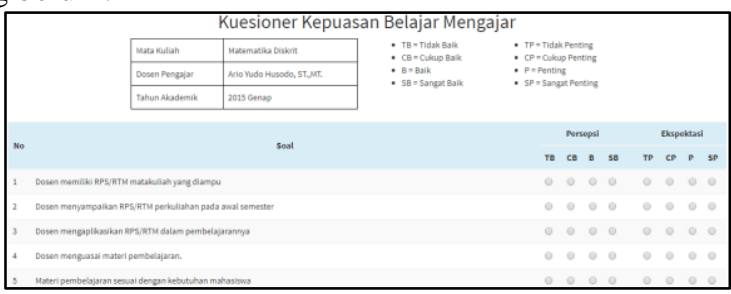

Gambar 14. Halaman isi kuesioner

Halaman isi kuesioner berisi kuesioner yang diisi oleh mahasiswa. Kuesioner berisi beberapa pertanyaan yang akan dijawab oleh mahasiswa. Terdapat keterangan mata kuliah yang diampu oleh dosen yang bersangkutan pada bagian atas laman ini.

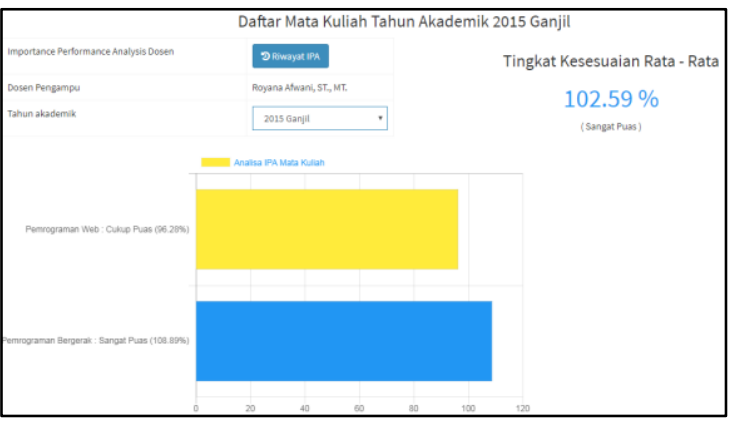

Gambar 15. Halaman daftar mata kuliah dari sisi dosen

Halaman daftar mata kuliah dari sisi dosen yang akan tampil adalah nama dosen, tahun akademik yang dinilai dan terdapat persentase kepuasan mahasiswa yang terdapat dibagian kanan atas. Dosen tersebut dapat mengecek persentase mata kuliah lain dengan grafik yang ada dibawah tahun akademik.

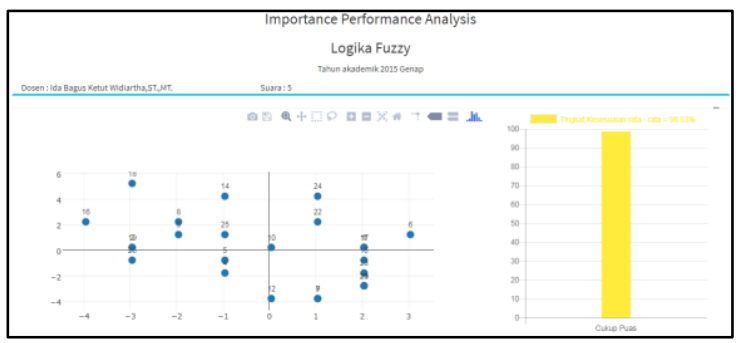

Gambar 16. Halaman hasil analisa IPA kuesioner (1)

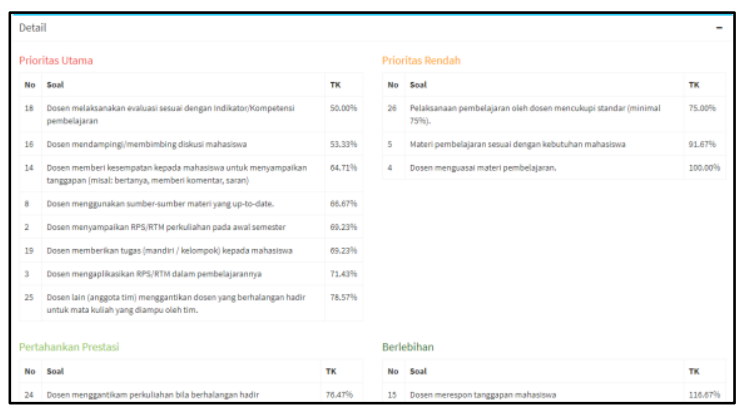

Gambar 17. Halaman hasil analisa IPA kuesioner (2)

Halaman hasil analisis IPA kuesioner yang ditampilkan diatas adalah tampilan dari sisi dosen. Tampilan halaman pada bagian atas terdapat nama mata kuliah sebagai keterangan judul. Terdapat pembagian menurut analisis IPA pertanyaan mana sajakah yang terdapat pada kuadran 1 sampai 4. Apabila terdapat di kuadran rendah maka akan dijadikan perbaikan oleh dosen yang bersangkutan kedepannya.

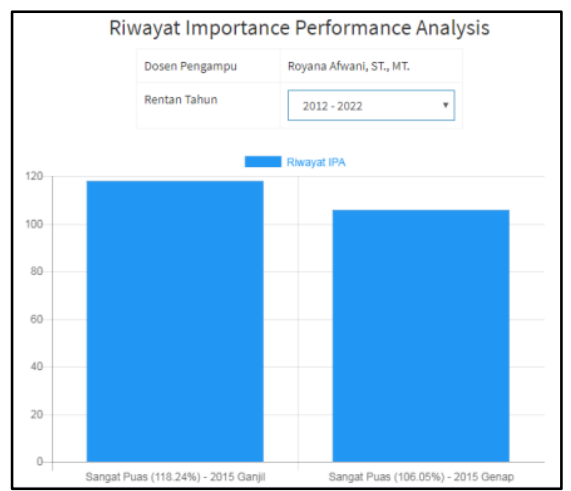

Gambar 18. Halaman riwayat IPA dosen

Halaman riwayat IPA dosen adalah halaman yang berisi diagram batang persentase untuk setiap dosen. Diagram batang digambarkan sesuai dengan mata kuliah dan tahun akademik yang telah diajarkan. 


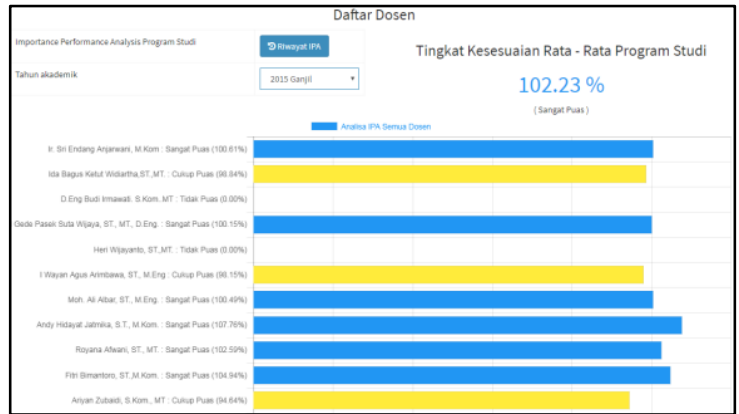

Gambar 19. Halaman daftar dosen oleh Ketua Program Studi

Halaman daftar dosen oleh Ketua Program Studi adalah laporan untuk Ketua Program Studi. Laporan tersebut berisi grafik kepuasan yang bersumber dari hasil kuesioner yang telah diisi oleh mahasiswa.

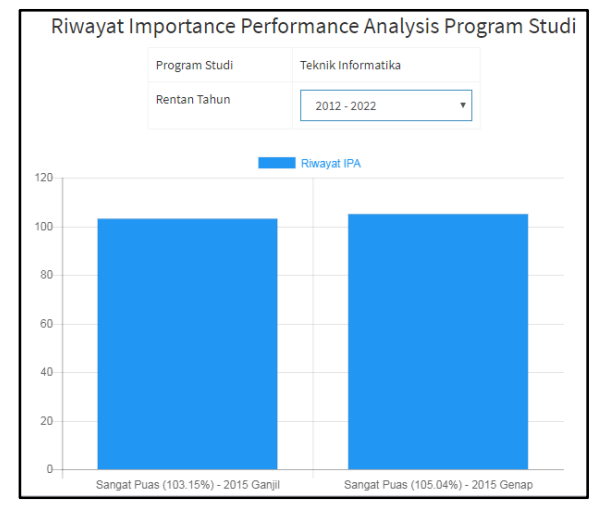

Gambar 20. Halaman riwayat IPA program studi

Halaman riwayat IPA program studi ini berisi rekapitulasi analisis kepuasan oleh kuesioner yang telah diisi mahasiswa. Grafik batang ini dikelompokkan berdasarkan rentan tahun yang diinginkan oleh Ketua Program Studi.

\section{Hasil Pengujian}

1. Pengujian black box

Keberhasilan pengujian black box tercermin dari fitur yang disediakan apakah telah berjalan sesuai dengan fungsinya. Fitur yang telah dibuat sebelumnya telah berjalan sesuai dengan fungsinya masing-masing.

\section{Pengujian Mean Opinion Score (MOS)}

Pengujiann MOS dilakukan dengan menerjemahkan hasil kuesioner menjadi beberapa kategori. Diantaranya adalah baik, netral, dan tidak baik [10], [11]. Pengujian ini dilakukan oleh beberapa pengguna yang akan menggunakan sistem yaitu mahasiswa, dosen, Ketua Program Studi dan admin. Pengujian akan melibatkan 30 mahasiswa, 9 dosen, 2 admin dan Ketua Program Studi. Pengujian dilakukan dengan menjelaskan sistem kepada pengguna, kemudian memberikan pengguna kesempatan untuk mencoba sistem secara langsung agar dapat memberikan penilaian terhadap sistem melalui pengisian kuesioner.
TABEL I. TABEL HASIL KUESIONER OLEH 30 MAHASISWA

\begin{tabular}{|c|c|c|c|c|c|c|c|c|c|}
\hline No & Pertanyaan & $\begin{array}{c}\text { SS } \\
\text { (7) }\end{array}$ & $\begin{array}{c}\text { S } \\
\text { (6) }\end{array}$ & $\begin{array}{c}\text { AS } \\
\mathbf{( 5 )}\end{array}$ & $\begin{array}{c}\text { N } \\
\mathbf{( 4 )}\end{array}$ & $\begin{array}{c}\text { ATS } \\
\mathbf{( 3 )}\end{array}$ & $\begin{array}{c}\text { TS } \\
\text { (2) }\end{array}$ & $\begin{array}{c}\text { STS } \\
(\mathbf{1})\end{array}$ & Ma \\
\hline 1 & Pertanyaan 1 & 14 & 15 & 1 & & & & & 6.43 \\
\hline 2 & Pertanyaan 2 & 14 & 12 & 2 & 1 & 1 & & & 6.23 \\
\hline 3 & Pertanyaan 3 & 10 & 13 & 7 & & & & & 6.1 \\
\hline 4 & Pertanyaan 4 & 13 & 14 & 2 & 1 & & & & 6.3 \\
\hline 5 & Pertanyaan 5 & 12 & 15 & 2 & & 1 & & & 6.23 \\
\hline 6 & Pertanyaan 6 & 15 & 10 & 3 & 2 & & & & 6.27 \\
\hline 7 & Pertanyaan 7 & 14 & 11 & 3 & 1 & 1 & & & 6.2 \\
\hline 8 & Pertanyaan 8 & 9 & 18 & 1 & 2 & & & & 6.13 \\
\hline \multicolumn{8}{|c|}{ MOS (Mean Opinion Score) } \\
\hline
\end{tabular}

Tabel II. TAbel hasil Kuesioner oleh Ketua Program STUDI

\begin{tabular}{|c|c|c|c|c|c|c|c|c|c|}
\hline No & Pertanyaan & $\begin{array}{l}\text { SS } \\
\text { (7) }\end{array}$ & $\begin{array}{c}\mathrm{S} \\
(6)\end{array}$ & $\begin{array}{l}\text { AS } \\
\text { (5) }\end{array}$ & $\begin{array}{c}\mathbf{N} \\
(4)\end{array}$ & $\begin{array}{c}\text { ATS } \\
\text { (3) }\end{array}$ & $\begin{array}{l}\text { TS } \\
\text { (2) }\end{array}$ & $\begin{array}{c}\text { STS } \\
\text { (1) }\end{array}$ & Ma \\
\hline 1 & Pertanyaan 1 & 1 & & & & & & & 7 \\
\hline 2 & Pertanyaan 2 & & 1 & & & & & & 6 \\
\hline 3 & Pertanyaan 3 & 1 & & & & & & & 7 \\
\hline 4 & Pertanyaan 4 & 1 & & & & & & & 7 \\
\hline 5 & Pertanyaan 5 & 1 & & & & & & & 7 \\
\hline 6 & Pertanyaan 6 & & 1 & & & & & & 6 \\
\hline 7 & Pertanyaan 7 & 1 & & & & & & & 7 \\
\hline 8 & Pertanyaan 8 & 1 & & & & & & & 7 \\
\hline \multicolumn{9}{|c|}{ MOS (Mean Opinion Score) } & 6.75 \\
\hline
\end{tabular}

TABEL III. TABEL HASIL KUESIONER OLEH 9 DOSEN

\begin{tabular}{|c|c|c|c|c|c|c|c|c|c|}
\hline No & Pertanyaan & $\begin{array}{c}\text { SS } \\
(\mathbf{7})\end{array}$ & $\begin{array}{c}\text { S } \\
(\mathbf{6})\end{array}$ & $\begin{array}{c}\text { AS } \\
\mathbf{( 5 )}\end{array}$ & $\begin{array}{c}\text { N } \\
\mathbf{( 4 )}\end{array}$ & $\begin{array}{c}\text { ATS } \\
\mathbf{( 3 )}\end{array}$ & $\begin{array}{c}\text { TS } \\
(\mathbf{2})\end{array}$ & $\begin{array}{c}\text { STS } \\
(\mathbf{1})\end{array}$ & Ma \\
\hline 1 & Pertanyaan 1 & 3 & 6 & & & & & & 6.33 \\
\hline 2 & Pertanyaan 2 & 1 & 8 & & & & & & 6.11 \\
\hline 3 & Pertanyaan 3 & 1 & 7 & 1 & & & & & 6 \\
\hline 4 & Pertanyaan 4 & 1 & 7 & 1 & & & & & 6 \\
\hline 5 & Pertanyaan 5 & 1 & 7 & & 1 & & & & 5.89 \\
\hline 6 & Pertanyaan 6 & 4 & 4 & 1 & & & & & 6.33 \\
\hline 7 & Pertanyaan 7 & 2 & 7 & & & & & & 6.22 \\
\hline 8 & Pertanyaan 8 & 5 & 4 & & & & & & 6.56 \\
\hline \multicolumn{8}{|c|}{ MOS (Mean Opinion Score) } \\
\hline
\end{tabular}

TABEL IV. TABEL HASIL KUESIONER OLEH 2 ADMIN

\begin{tabular}{|c|c|c|c|c|c|c|c|c|c|}
\hline No & Pertanyaan & $\begin{array}{c}\text { SS } \\
\text { (7) }\end{array}$ & $\begin{array}{c}\text { S } \\
\text { (6) }\end{array}$ & $\begin{array}{c}\text { AS } \\
\text { (5) }\end{array}$ & $\begin{array}{c}\text { (4) } \\
\text { (4) }\end{array}$ & $\begin{array}{c}\text { ATS } \\
(\mathbf{3})\end{array}$ & $\begin{array}{c}\text { TS } \\
\text { (2) }\end{array}$ & $\begin{array}{c}\text { STS } \\
\text { (1) }\end{array}$ & Ma \\
\hline 1 & Pertanyaan 1 & 1 & 1 & & & & & & 6.5 \\
\hline 2 & Pertanyaan 2 & & 2 & & & & & & 6 \\
\hline 3 & Pertanyaan 3 & & 1 & 1 & & & & & 5.5 \\
\hline 4 & Pertanyaan 4 & 1 & & 1 & & & & & 6 \\
\hline 5 & Pertanyaan 5 & 1 & 1 & & & & & & 6.5 \\
\hline 6 & Pertanyaan 6 & & 2 & & & & & & 6 \\
\hline 7 & Pertanyaan 7 & 1 & 1 & & & & & 5.5 \\
\hline \multicolumn{8}{|c|}{ MOS (Mean Opinion Score) } \\
\hline
\end{tabular}

Untuk mencari persentase jawaban kuesioner kategori Good dihitung dengan Persamaan (1).

$$
\text { Good }=\frac{\sum p i(S S, S, A S)}{n} \times 100
$$

dimana:

Good : Persentase jawaban kuesioner kategori Good.

$p i(S S, S, A S)$ : Jumlah skor kali bobot nilai suatu atribut pertanyaan dengan pilihan skala likert sangat setuju, setuju, dan agak setuju.

$\mathrm{n}$ : Jumlah responden.

Untuk mencari persentase jawaban kuesioner kategori Neutral dihitung dengan Persamaan (2).

$$
\text { Neutral }=\frac{\sum p i(N)}{n} \times 100
$$

dimana :

Neutral : Persentase jawaban kuesioner kategori Neutral. 
$p i(N)$ : Jumlah skor kali bobot nilai suatu atribut pertanyaan dengan pilihan skala likert netral.

$\mathrm{n}$ : Jumlah responden.

Untuk mencari persentase jawaban kuesioner kategori Bad dihitung dengan Persamaan (3).

$$
\mathrm{Bad}=\frac{\sum p i(\text { ATS,TS,STS })}{n} \times 100
$$

dimana:

Bad : Persentase jawaban kuesioner kategori Bad.

pi $(A T S, T S, S T S)$ : Jumlah skor kali bobot nilai suatu atribut pertanyaan dengan pilihan skala likert agak tidak setuju, tidak setuju dan sangat tidak setuju.

n : Jumlah responden.

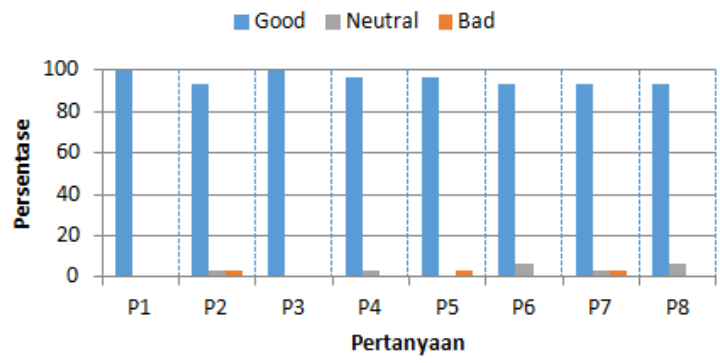

Gambar 21. Grafik persentase jawaban kuesioner oleh 30 mahasiswa berdasarkan tingkat kategori Good, Neutral dan Bad

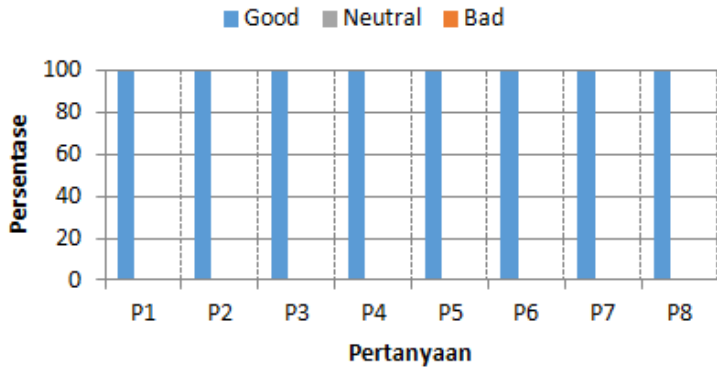

Gambar 22. Grafik persentase jawaban kuesioner oleh Ketua Program Studi berdasarkan tingkat kategori Good, Neutral dan Bad

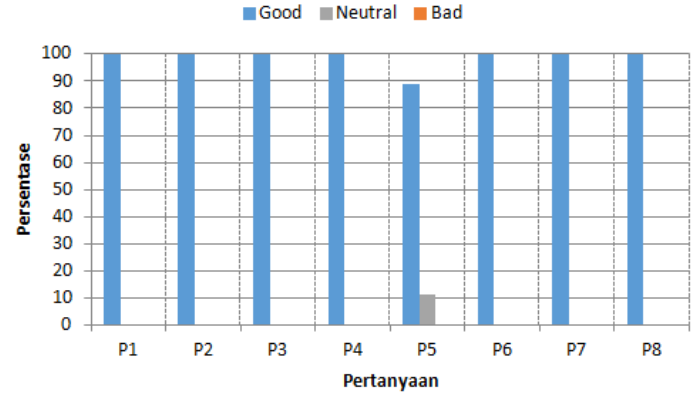

Gambar 23. Grafik persentase jawaban kuesioner oleh 9 dosen berdasarkan tingkat kategori Good, Neutral dan Bad

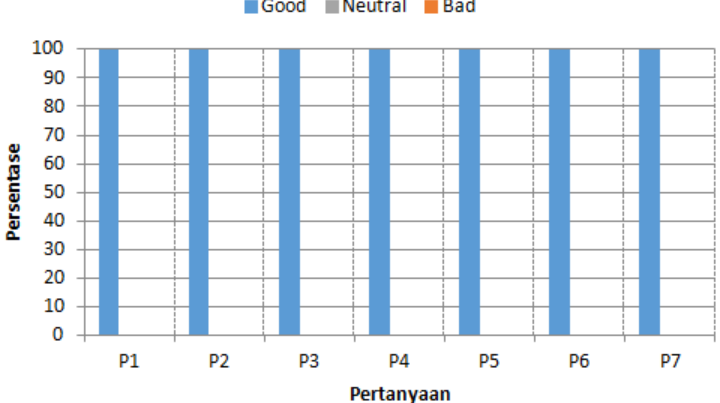

Gambar 24. Grafik persentase jawaban kuesioner oleh 2 admin berdasarkan tingkat kategori Good, Neutral dan Bad

TABel V. Persentase RATA - RATA JAWABAn KUESIONER

\begin{tabular}{|c|c|}
\hline Kategori & Persentase \\
\hline Good & $98.61 \%$ \\
\hline Neutral & $1.07 \%$ \\
\hline Bad & $0.31 \%$ \\
\hline
\end{tabular}

Berdasarkan dari pengujian MOS yang dilakukan oleh mahasiswa, dosen, Ketua Program Studi dan admin dengan hasil uji MOS $\geq 5.00$ dan persentase rata - rata jawaban kategori Good dari semua responden adalah $98.61 \%$ menunjukan bahwa sistem informasi kepuasan belajar mengajar telah berjalan dengan baik (lihat Tabel V).

\section{KESIMPULAN}

1. Kesimpulan

$\checkmark$ Dari hasil pengujian black box, Sistem Informasi Kepuasan Belajar Mengajar yang dibuat telah dapat meakukan analisis terhadap jawaban kuesioner yang diisi oleh mahasiswa yang bersangkutan. Analisis tersebut mengelompokkan menjadi beberapa kategori prioritas berdasarkan pandangan dan ekspektasi mahasiswa menggunakan metode IPA (Importance Performance Analysis).

$\checkmark$ Berdasarkan hasil pengujian black box, semua fitur yang telah dibuat dapat berjalan sesuai dengan fungsinya masing - masing. Pengujian dilakukan dengan input data yang berbeda-beda, sehingga menunjukan bahwa fungsi yang ada dalam sistem informasi kepuasan belajar mengajar telah berjalan sesuai dengan fungsinya.

$\checkmark$ Berdasarkan dari jawaban kuesioner Mean Opinian Score oleh semua tipe pengguna dengan persentase rata - rata jawaban kuesioner kategori Good adalah $98.61 \%$, dapat disimpulkan bahwa sistem ini berguna bagi PSTI untuk melihat tingkat kepuasan mahasiswa terhadap proses belajar mengajar yang terdapat di PSTI.

2. Saran

$\checkmark$ Semua sistem di program studi mengimplementasikan teknologi Single Sign On agar SIKBM dan SIA UNRAM memiliki satu sistem autentikasi sehingga pengguna cukup 
memiliki satu akun untuk digunakan di semua sistem.

$\checkmark \quad$ SIKBM perlu menyediakan API untuk diakses oleh SIA UNRAM untuk mengetahui status pengisian kuesioner mahasiswa.

\section{DAFTAR PUSTAKA}

[1] A. Heryandi, "Pembangunan Sistem Informasi Pengisian Survey Evaluasi Perkuliahan Online di Universitas Komputer Indonesia," Komputa J. Ilm. Komput. dan Inform., 2012, doi: 10.34010/komputa.v1i2.65.

[2] Z. R. I. Mautofani, P. F. Opit, and R. Rottie, "Analisis Kepuasan Mahasiswa Terhadap Pelayanan Unika De La Salle," pp. 91-99.

[3] I. Sitaridis and F. Kitsios, "Course Experience Evaluation using Importance Performance Analysis," 2019 IEEE Glob. Eng. Educ. Conf., pp. 859-862, 2019.

[4] S. R. Magal and N. M. Levenburg, "Using importance-performance analysis to evaluate $\mathrm{e}$ business strategies among small businesses," Proc. Annu. Hawaii Int. Conf. Syst. Sci., vol. 00, no. C, p. 176, 2005, doi: 10.1109/hicss.2005.661.

[5] B. Harijanto and Y. Ariyanto, "Sistem Informasi Pengukuran Kepuasan Pelanggan (Studi Kasus Politeknik Negeri Malang)," J. ELTEK, 2014.

[6] Faturrachman, Analisa Kualitas Pelayanan pada Bagian Tata Usaha Berdasarkan Tingkat Kepuasan
Mahasiswa Menggunakan Metode IPA (Importance Performance Analysis) dan KANO. Universitas Islam Sunan Kalijaga, Yogyakarta, 2015.

[7] H. Purnomo, Sistem Informasi Analisa Kuesioner Penggunaan Layanan Internet Menggunakan Metode IPA (Importance Performance Analysis) dan CSI (Customer Satisfaction Index). Universitas Mataram, 2014.

[8] P. W. Subroto, B. Tola, and A. S. Suparno, "The Use of Importance-performance Analysis in Evaluating the Teachers' Professional Development Program," no. Icels 2019, pp. 376-386, 2020, doi: $10.5220 / 0008999303760386$.

[9] W. E. Y. Keong, "Importance-performance analysis of e-learning technologies in Malaysian higher education," Proc. - 2017 Int. Symp. Educ. Technol. ISET 2017, pp. 24-28, 2017, doi: 10.1109/ISET.2017.14.

[10] R. Fitriyanti, L. Lindawati, and A. Aryanti, “Analisis Perbandingan Mean Opinion Score Aplikasi VoIP Facebook Messenger dan Google Hangouts menggunakan Metode E-Model pada Jaringan LTE," ELKOMIKA J. Tek. Energi Elektr. Tek. Telekomun. Tek. Elektron., vol. 6, no. 3, p. 379, 2018.

[11] S. Syaifullah, I. G. P. S. Wijaya, and A. Y. Husodo, "Sistem Informasi Kepuasan Layanan Administrasi Akademik Berbasis IPA (Importance Performance Analysis) Studi Kasus Fakultas Teknik Universitas Mataram," J. Comput. Sci. Informatics Eng., vol. 2, no. 1, 2018. 